\title{
The challenges of using disruptive technologies/innovations in a cyber- landscape
}

\author{
Mary Kiernan \\ University of Greenwich
}

\section{Introduction}

The term 'disruptive technologies' was coined by Clayton Christensen in his 1997 book 'The Innovator's Dilemma'. Disruptive technologies are new technologies that, even though often lacking refinement and performance, unexpectedly replace an established technology. One of them, iTunes, completely disrupted the music market. Another, Minecraft, is a version of online Lego and was created by Markus Persson as a gaming website for his friends. It was initially afflicted with bugs, the graphics are poor and it uses cursor-key-driven pixelated blocks as building blocks. At first, people built structures as a defence against nocturnal monsters, but, as the game grew, players worked together to create "wonderful, imaginative things" (minecraft.net). In spite of its defects, it is very easy to use and is, in essence, an online Lego kit that has effectively taken over the online Lego market. Lego did produce Lego Universe, but, though the company had a large customer base, there was no online social network to build on. Having introduced the social network, too late, in 2012, Lego was obliged to withdraw Lego Universe later in the same year. As of 25 March 2015, 18,990,788 people have bought Minecraft (www.minecraft.net/stats).

Minecraft started with friends, as did Facebook, and so socialisation was already embedded into the online environment. How can we ensure socialisation happens early in any online course? This paper outlines the author's prior research into and experiences of Massive Open Online Courses (MOOCs) and argues that socialisation is the key to any successful cyber-landscape.

\section{Disruptive Innovation in arguably the first Massive Open Online Course (MOOC)}

In 1999, the Open University piloted a course entitled 'You, Your Computer and the Net'. The author was part of the delivery team and undertook research into the perceptions of the tutors, whose verdict was that the technology was slow and bug-infested and the quality of the online materials was inferior to that of the hard copies; they also felt that guidance for their students and facilitation of group discussions would be managed much better by faceto-face contact. In 2000 , the course was launched - with 12,000 students enrolled, it was the largest online course at the time - and received favourable feedback from the students (Kiernan et al, 2000, 2003).

A key factor in the success of the course was the use of the conference facility (for early socialisation activities), in which students and tutors could interact. Further research into what tutors felt about the course revealed that, though their primary focus had initially been pedagogical, they had rapidly become aware of the importance of socialisation in this online medium. Yet more research in 2006 highlighted once again the significance of socialisation, as well as demonstrating a direct correlation between students' online input in the early stages of the course and their final course mark (Kiernan, 2008). 


\section{Experiences as a student on a Massive Open Online Course (MOOC)}

MOOCs have increased in popularity in recent years and, in 2012, there were over 6.7 million online learners (Sloan report, January 2013). Barber et al (2013) forecast that, owing to MOOCs, the business models for higher education would collapse, just as Minecraft had led to the demise of Lego Universe. When a colleague completed the MOOC course and reported favourably on his experiences (Valsamidis, 2012), I was stimulated to study on the Open Learning Design Studio Massive Open Online Course (OLDS MOOC), 'Learning Design for a 21st Century Curriculum', a course designed as a 'c-MOOC', using connectivism learning theory and having a more social approach to learning, rather than as an ' $x$-MOOC', which involves a more individual learning style and uses a cognitivebehaviourist approach.

This nine-week course started in January 2013 and was led by the Open University's Institute of Educational Technology, in partnership with the University of Greenwich, Goldsmiths University, Heriot-Watt University, University of Leicester, University of London and the University of Oxford. The OLDS MOOC was a collaborative, project-based course with a structured set of activities that "reflect[ed] a proposed process for a design inquiry project. In such a process, designers identify a (learning/curriculum) design challenge, explore it to gain an understanding of its context and driving forces, generate possible solutions, implement a solution and reflect on the process as a whole and its outputs." (www.olds.ac.uk).

After an easy enrolment process, I felt highly motivated and full of anticipation for the course, but an unavoidable interruption prevented my starting immediately and I discovered, at my delayed login after two or three days, that there had already been many postings: I had missed the boat. My morale was hardly improved by this paragraph in a tutor email, received midway through the first week: "As the weekend comes to a close in the UK, we reach the midpoint of week 1 . There is much to celebrate, so far, with over 800 posts in the open forum, and over 100 project clouds created in the Dreambazaar. They range in subject from the Internet of Things to Leadership to constructing MOOCs." I realised that I had missed the initial formation by the students of their study groups and felt both dejected and isolated; however, I was not completely alone, as another student posted (http://cloudworks.ac.uk/cloud/view/7298) what mirrored my own feelings:

"Coming to the end of the first week I feel that my glider is still stuck in turbulence and my compass is broken. Occasionally I hear messages on my radio giving me instructions of where to steer a safe passage (thank you Yishay!) but these are mostly drowned out by the air as it rushes around this delicate shell..."

The lack of early socialisation in the course meant that, in spite of my attempts to regain what I had lost, I became (to my own disappointment) a 'lurker', following and reading posts but not posting or interacting myself. I was experiencing exactly what my research had shown, that those who do not socialise early do not maximise their learning on the course (Anderson and Dron, 2010; Kiernan et al 2008).

My subsequent observations of the forum indicated a few very active members and led me to conclude that a significant number of students had either become lurkers like me or given up the course. Jeff Haywood, Professor of Education and Technology at Edinburgh 
University, commented on the $12 \%$ completion rate of Edinburgh's first batch of MOOCs: "While completion rates on nearly all moocs are low - somewhere below $10 \%$ - this doesn't matter ... Many sign up to "window shop" or dip in and out, which is no bad thing. ... Edinburgh's students came mostly from the US and UK and those who responded to the survey said the courses met or exceeded expectations" (Pozniak, 2013 online).

\section{Socialisation is the key}

Many studies indicate that socialisation is key to developing an effective online learning environment (Chang, 2015; Khalil \& Ebner, 2013; Salmon, 2013). My recent research into developing computational thinking using an online game also highlighted this, as students asked for the ability to socialise with fellow students to share experiences and provide mutual support (Kazimoglu et al, 2011).

Mackness et al (2010) found that, in their MOOC, "[t]he more autonomous, diverse and open the course, and the more connected the learners, the more the potential for their learning to be limited by the lack of structure, support and moderation normally associated with an online course, and the more they seek to engage in traditional groups as opposed to an open network." Though there is an array of types of MOOCs, some course-led and some for like-minded people to share their knowledge (for example, how to use constructivism within courses), I argue that socialisation underpins all of them and is key to students' maximising their potential, regardless of the medium.

An evaluation of the OLD MOOCS course states: "The example of collaborative group working has been a particularly interesting case study with evidence suggesting that whilst this was encouraged and built in to the course design (and indeed attempted by over a hundred participants), it did not work as envisaged so those who chose to continue did so by working by themselves but with the more general support of course community." Cross (2013). This certainly was true of my experience, as outlined above. I did not maximise my learning potential (http://oro.open.ac.uk/37836/), as I was trying to find a role within the group and thus felt too disempowered to post. Preece's (2014) large-scale research, where $29.7 \%$ of learners did not contribute because they were still finding out about the group, corroborates my experience. Socialisation, managed in a non-threatening way, must therefore happen at the very beginning of any course, but incorporating socialisation within a MOOC is challenging. It would be helpful to suggest that students should form groups of small size; it would certainly help to encourage all students to share a little about themselves and for the moderator/lead participant to do the same, as well as to provide a photograph or avatar. A simple introductory group task/exercise would enable participation and formation of group norms and create a congenial environment for subsequent activities.

\section{Conclusions}

We are currently facing rapid changes in how we can both deliver learning material and support students. The added flexibility and enhancement of 'Bring Your Own Devices' + cloud technology (a "tablet+app+cloud" combination) will enable minor tutor-based alterations in learning provision to become major changes in student involvement and engagement. 
Too often, educators want to use the latest technology because they believe it will enhance learning, but we must remember, as Naughton (2009) stresses: “Don't confuse existing forms with the functions that they enable. It's the functions that matter. Forms may be transient, the product of historical or technological circumstances." The biggest challenge for online education is how to engender socialisation quickly at the start of a course. We now have wonderful opportunities to enhance student learning at a time, place and format that meets all of their needs. However, as my research and current experience show, early socialisation is still the foundation on which effective online vibrant communities develop. Without this, regardless of how well-structured the learning material and activities are, retention and achievement rates will remain very low.

\section{Reference list}

Anderson, T. and Dron, J. (2010) 'Three generations of distance education pedagogy.' The International Review of Research in Open and Distance Learning, 12 (3), 80-97.

Chang, Y. (2015) 'The relationship between perceptions of an innovative environment and creative performance in an online synchronous environment.' Computers in human behaviour, 49, 38-43.

Cross, S. (2013) Evaluation of the OLDS MOOC curriculum design course: participant perspectives, expectations and experiences. OLDS MOOC Project, Milton Keynes. Available at: http://oro.open.ac.uk/37836/ (Accessed: 1 April 2013).

Davis, H.C., Dickens, K., Urrutia, L., Sanchéz, V.M, del Mar, M. and White, S. (2014) 'MOOCs for Universities and Learners: An analysis of motivating factors.' In: 6th International Conference on Computer Supported Education, 01-03 April 2014.

Pozniak, H. (2013) 'Moocs are the clever way to keep up to date.' The Guardian, 18 June 2013, Available at: http://www.theguardian.com/education/2013/jun/18/leading-unis-launchfree-courses (Accessed 1 April 2014).

Kazimoglu, C., Kiernan, M., Bacon, L. and MacKinnon, L. (2011) 'Understanding computational thinking before programming: developing guidelines for the design of games to learn introductory programming through game-play.' International Journal of Game-Based Learning (IJGBL), 1(3), 30-52.

Khalil, H. and Ebner, M. (2013) 'How satisfied are you with your MOOC? - A Research Study on Interaction in Huge Online Courses.' Proceedings of World Conference on Educational Media and Technology 2013 (830-839). Association for the Advancement of Computing in Education (AACE).

Kiernan, M. (2000) 'Does the medium dictate the message? How 30 minutes changed the perceptions of new on-line conference moderator.' Vienna: ICT in Education 2000 Association for Computer Machinery.

Kiernan, M. (2008) 'Effective e-Moderation in e-Courses.' Higher Education Academy eLearning Conference, Greenwich, June 2008.

Kiernan, M., Thomas, P., Woodroffe, M. (2003) 'Signposts in the Sand.' Proceedings of the World Conference on E-Learning in Corporate, Government, Healthcare, and Higher Education.

Lee, S., Park, D., Han, I. (2014) 'New members' online socialization in online communities: The effects of content quality and feedback on new members' content-sharing intentions,' 
Computers in Human Behavior, 30, 344-354, ISSN 0747-5632, Available at: http://dx.doi.org/10.1016/j.chb.2013.09.015 (Accessed: 1 April 2015).

Mackness, J., Fai, S., Mak, J., Williams, R. (2010) 'Ideals and Reality of Participating in a MOOC.' 266-275 Proceedings of the 7th International Conference on Networked Learning 2010. Dirckinck-Holmfeld L, Hodgson V, Jones C, de Laat M, McConnell D \& Ryberg (eds.) T266 ISBN 978-1-86220-225-2.

Preece, J., Nonnecke, B., Andrews, D., Voutour, R. (2014) 'Online Lurkers Tell Why.' Proceedings of the Tenth Americas Conference on Information Systems, New York.

Salmon, G. (2013) e-Tivities $2^{\text {nd }}$ Edition. Taylor \& Francis Ltd., Routledge ISBN10: 0415881765 ISBN13: 9780415881760.

Valsamidis, T. (2012: 'A learner's experience of a massive open online course.' Compass (the Teaching and Learning Journal of the University of Greenwich) 6. 